\title{
Practice-oriented technologies as a means of forming communicative competences of students
}

\author{
E.K. Ametova ${ }^{1 *}$, E.M. Sukhodolova ${ }^{2}$, and O.V. Teslenko ${ }^{3}$ \\ ${ }^{1}$ V.I. Vernadsky Crimean Federal University, Simferopol, Russia \\ ${ }^{2}$ Federal State Budgetary Educational Institution "Gzhel State University", Electroizolyator, Russia \\ ${ }^{3}$ State Educational Institution of Higher Education of the Moscow Region of the Moscow Region \\ State University, Mytischi, Russia
}

\begin{abstract}
This research is devoted to the consideration and study of the system of practice-oriented technologies as the main tools for the formation of communicative competencies of modern university students. The essence and specificity of both practice-oriented technologies and communicative competencies are considered, which allows to carry out the most complete and objective analysis of this topic in future. The object of the research is precisely in the specifics of the formation of such competencies, which is complicated by the current problems in the field of professional training of students. The role of individual elements of practice-oriented technologies in the system of forming of the professional culture of modern specialists is comprehended and actualized. In the course of the study, the authors identified the key method that laid the foundation for this work, namely the questionnaire method. The topic of the survey was to identify the role of practice-oriented technologies as key means of forming the communicative competencies of modern students. The respondents were the teaching staff of several leading universities of the Republic of Crimea. In our opinion, the results of such a questionnaire and of this study as a whole can serve as an important foundation for further research on this topic, since they are fully reflected in the form of a comprehensive conclusion, which is based primarily on the analytical and reflective activities of modern teachers. The results of the study can be found in the final part of it.
\end{abstract}

\section{A problem statement}

The communicative competences today are among the most significant for all members of society. Thanks to their harmonious and holistic development, the future specialist can be guaranteed to pass the stage of socialization successfully and to become not only a competitive, relevant and mobile specialist, but also to prove himself as a socially active,

*Corresponding author: ipcs-profped@yandex.ru 
developed and competent member of society, able to express his thoughts and to establish interpersonal communication with other subjects of the state's socio-cultural space.

In this regard, a number of problems related to the formation of such competencies arise before modern higher education, which produces the so-called "human potential" consisting of specialists of different profiles and levels. The key problem of this research can be considered as the insufficient understanding of the importance of communicative culture and the means that ensure its effectiveness and rapid development by native teachers. Thus, it seems to us necessary to conduct such a study that is able to clarify as clearly as possible the key aspects associated with communicative competencies.

\subsection{The objective of the work}

The native pedagogical science pays considerable attention to the issue of the formation of students' communicative competencies through the use of various currently known technologies. In this context, we believe that the works of such native authors as T.A. Belova, N.V. Grigorieva, N.P. Bakharev, E.A. Dragunova, Yu.M. Vasina, E.V. Panferova, A.E. Yakovleva, O.F. Karmadonova, E.N. Belyaeva, V.V. Okhotnikova, N.N. Surtaeva, E.M. Bastrikov, F.B. Abaeva, E.E. Dudkovskaya and others are the most significant.

E.V. Kirsanov, V.I. Chernenko, I.V. Kiyan, N.V. Lomovtseva, E.S. Polat, M.V. Moiseeva, A.E. Petrov, P.L. Pekker, A.V. Khutorskoy and others.

The studies of the above-mentioned authors laid the basis for the development of this topic and became the foundation for the construction of this study. They reflect the main theoretical postulates associated with the formation of communicative competencies in students, as well as with the active use of practice-oriented technologies in modern teaching practice. These works created such a global and wide picture that allows not only to consider the key focal points needed for studying, but also to draw attention to some secondary problematic issues. Many of them are cited and mentioned by us consciously in the subsequent parts of the article.

\section{Materials and the results of the research}

This research aims to study the process of the formation of communicative competencies among university students, which occurs through the active introduction of practiceoriented technologies into the educational process that optimize and modernize the educational environment. The achievement of this goal is possible through the implementation of smaller tasks arising on the path of research:

- identifying the problems that exist today in the system of forming communicative and other competencies in the modern educational space;

- determination of the most effective practice-oriented technologies aimed at optimizing the process of forming communicative competencies;

- conducting an analytical study in the form of a questionnaire survey of the teaching staff of the leading Crimean universities and comparing the experience of various teachers involved in the study of this topic.

In our opinion, only the achievement of the above-mentioned tasks can create a new vector for the development and studying of this topic, as well as to become a significant basis for the formation of more complicated and complex research. Besides, only thanks to this, it is possible to bring the above-mentioned problem to a fundamentally new level of pedagogical comprehension, which will allow modern teachers to take an active part in the search for more perfect tools for solving this and related problems in future. 
Today higher education is aimed primarily at creating the civil and social potential of the state, which will be able to develop various industries, including education, economy, culture, etc. in future. In this regard the question of the need of forming various competencies of future specialists, including communication specialists, arises. They actively influence not only on the communicative culture of a person, but also on his educational, professional, social activities [16].

The communicative competencies in the modern sense should be understood as a certain set of skills and abilities that allow the subject of the sociocultural space to make an independent choice in the field of speech behavior models in accordance with the communication situation $[20 ; 23]$. The essence of such competencies lies in the adequate assessment and timely application of speech abilities at one point or another in the process of interpersonal communication. Moreover, such communication should be carried out on time and as holistically as possible, which depends precisely on the communicative competencies of the individual.

All the subjects of modern society are in constant interaction with each other. This is an integral part of every social structure, which includes individuals of a different order. To abandon verbal communication today seems almost impossible, in connection with which the development of the above-mentioned competencies becomes the main object in the system of interpersonal relationships and is a fundamental factor in the harmonious development of a person's personality. It is important to mention that communicative abilities are manifested not only in the process of direct speaking, but also in the process of listening, thinking, analyzing, reading and writing [3;5].

The development of these aspects undergoes a long history, which originates from the moment the child's first speech abilities appear. It all starts with the simplest sounds, words, phrases and sentences. Thus, there is a natural development of communication skills and the basis for their continuous learning is formed. Moreover, such skills are extremely influential in the field of career guidance and becoming a person as a professional. This is due to the fact that, while demonstrating communication competence, a person, based on its quality and general level, focuses on certain areas of activity, which are compared precisely with its quality and level. It is in this connection that modern educators need to address the development of these skills.

In this case pedagogical influence becomes highly important for the development of many personal qualities of a specialist: independence, the ability to find a timely way out of the current situation, to realize his place and role in society, to self-actualize his activities, etc. Except of this, the interaction with various subjects of social relationships, the system of cognitive, analytical and reflective thinking are significantly improved. Proceeding from this, communicative competences cannot be considered as competences of speaking, listening and understanding exclusively. It is important to understand their vastness, versatility and integrity.

The specificity of this phenomenon lies in the fact that communication learning is possible only through the transferring of their own communicative experience to students from the teacher's side. The former should not only possess the necessary competencies, but also be able to build his speech and thoughts in the way students do not have any questions regarding his authority and understanding of the essence of communication. There should be a full-fledged development of communicative streams in the very structure of a higher educational institution, which forms an active socio-cultural space with appropriate communication ways.

In this regard it would be fair to note the importance of a personality-oriented approach - the leading approach up to date, in accordance with the main statements of which the personality of the student, his creative and professional potential and also the ability to interact with other members of society become the center of the educational process and the 
entire educational system. According to this, the teacher needs to pay special attention to the organization of the educational process, the most favorable for the formation of the communicative culture of each student separately $[1 ; 14 ; 21]$.

After determining the essence, specificity, meaning and pedagogical orientation of communicative competencies acquired by students in the process of professional training at a university, it seems to us especially logical to study the issue of the typology of these competencies.

In the opinion of many native scientists researching this topic, there are several types of communicative competencies:

- grammatical, or linguistic;

- sociolinguistic;

- discursive;

-strategic [13].

The linguistic competence is a set of skills associated with direct command of speech and language in general. It includes the ability to integrate the forms and meanings of linguistic means, as well as to support their mutual connection [4]. It is directly related with the competent and up-to-date usage of certain linguistic means, and includes such levels as phonology, vocabulary, semantics, grammar, which fully reflect the essence of the language and oral, written speech of a person [16]. Such competence lies at the heart of all interpersonal communication and mental activity, expression and construction of one's own thoughts.

Speaking about the sociolinguistic competence, it is impossible not to note the importance that the context of speech plays in its structure. The fact is that the language undergoes certain changes over time and becomes more flexible and unpredictable [23]. It directly depends on the time interval within which it develops and functions, in connection with which it would be fair to note the need of forming a certain spatial system of thinking, which will allow a person to understand the speech of his contemporaries and to correlate, adapt his speech accordingly. It is important not only to be aware of the modern state of the language in the system of international communication, but also to be able to use certain language means depending on the situation [26; 27]. For example, today it would be extremely illogical to use archaisms that are significantly inferior to modern youth slang in everyday speech. It is the most correct to adapt your speech to the age category of the social group in which the person interacts. This is what a separate layer of modern higher education should be devoted to, in our opinion.

The discursive competence is especially associated with mental activity in the field of perception and processing of information received by a person from the outside. It includes the skills and abilities of a communicative nature, aimed at the correct interpretation of messages arriving to a person, as well as at transferring the maximum possible set of types of communications and their elements, depending on the situation. In relation to this type, it is important to note the coherence and meaningfulness of communication activities, which become the main feature of a competent and harmoniously developed person in the communicative plan [7]. The essence of a person's narration, in accordance with this, should not only be full of meaning, but also represent an integral sequential structure, a logical connection. Moreover, this type is often manifested in a narrative that requires a particularly emphasized logical sequence: in a detailed retelling of certain events, in the content of a work or in writing a scientific work.

Such type of communicative competence as strategic competence pursues the goal of building a system of skills of such an order that will allow a person to build the most comfortable and effective communication, to identify and to correct mistakes that exist during it. It includes a set of tactics that are designed to adapt speech to the situation as much as possible and to make it more literate and unambiguous, without incorrect subtexts 
and interpretations. In addition, this group also includes the system of non-verbal language, which consists of postures, gestures and facial expressions [10]. Through the qualitative and comprehensive development of such competence, you can maximize the effect of your own speech, as well as to control the course of communication, directing it in the necessary vector.

As noted by M.M. Olesova, native universities were aimed at transferring to potential specialists a system of fundamental knowledge that can optimize their professional activities for a rather long period of time. At the same time, in the system of higher education some institutions, which accepted students for industrial practice, had been taking their place, that increased the practical tools of future graduates. At the moment, such a system is invalid, and therefore a university faces new tasks: not only to provide students with the necessary knowledge of a fundamental and applied nature, but also to organize their practical activities independently in such a way that they develop practical competencies for further professional success. It is in accordance with this, the researcher notes, that there is a need to move to the application of practice-oriented technologies in various areas of modern higher education [18].

Many native researchers understand practice-oriented technologies as a set of certain means, mechanisms and methods of educational activity that make it possible to realize the goals set in the course of any activity in the most effective way $[2 ; 5 ; 7 ; 8 ; 12 ; 15 ; 22]$.

Today the country's leading universities are introducing practice-oriented technologies in the process of forming students' communicative competencies. In this regard it seems to us especially necessary to consider their application in practice by analyzing the results of the survey, aimed at identifying the effectiveness of certain leading technologies. Let us consider and analyze these results, presented in the table below, and also explain the essential and specific aspects of each of these technologies.

Table. Evaluation of the effectiveness of the application of practice-oriented technologies (left column) in the process of developing students' communicative competencies (expressed in \%).

\begin{tabular}{|l|c|c|c|c|}
\hline & $\begin{array}{c}\text { Absolute } \\
\text { efficiency }\end{array}$ & $\begin{array}{c}\text { Partial } \\
\text { efficiency }\end{array}$ & $\begin{array}{c}\text { Partial in } \\
\text { efficiency }\end{array}$ & $\begin{array}{c}\text { Absolute in } \\
\text { efficiency }\end{array}$ \\
\hline $\begin{array}{l}\text { Game and interactive } \\
\text { technologies }\end{array}$ & $\mathbf{4 1 , 6}$ & 32,5 & 16,5 & 9,4 \\
\hline $\begin{array}{l}\text { Technologies of making group } \\
\text { projects }\end{array}$ & $\mathbf{5 5 , 1}$ & 21,3 & 11,4 & 12,2 \\
\hline Dialogue activities & $\mathbf{3 5 , 6}$ & 29,1 & 17,2 & 18,1 \\
\hline $\begin{array}{l}\text { Solving practical problems in } \\
\text { modular learning conditions }\end{array}$ & 26,4 & $\mathbf{4 3 , 9}$ & 13,2 & 16,5 \\
\hline $\begin{array}{l}\text { Performing creative } \\
\text { assignments }\end{array}$ & $\mathbf{5 2 , 6}$ & 20,2 & 17,6 & 9,6 \\
\hline $\begin{array}{l}\text { Self-education in the field of } \\
\text { acquiring communicative } \\
\text { competencies }\end{array}$ & $\mathbf{7 0 , 6}$ & 9,5 & 11,3 & 8,6 \\
\hline
\end{tabular}

As it can be seen from the results of the open questionnaire, almost all of the abovementioned practice-oriented technologies, aimed at the formation of students' communicative competencies, in practice have shown themselves in the best possible way. The interactive forms of education $(41.6 \%$ of respondents considered them to be effective ones) today constitute the main potential of educational activities in the field of professional training and student motivation. They are aimed primarily at the development of communicative selectivity and understanding of linguistic means.

By means of technologies of making group projects (55.1\%, respectively), students have the opportunity to establish interpersonal communication in accordance with the 
situation, as well as to test their speech abilities in an atmosphere close to real professional activity [27].

The dialogue activity (35.6\%) has become one of the most controversial aspects, since not all teachers agreed on its importance for the formation of a communicative culture. Dialogue activity is important exclusively for the oral and mental structures of communication, while the rest remain unused, according to teachers [11].

The solution of practical problems in the conditions of modular training (43.9\%) today acquires new significance in the system of forming students' communicative competencies, since the modular system presupposes careful comprehension and sequential presentation of the knowledge gained during a specific period of study. The communicative activity of the student, therefore, is formed on the basis of a logical and consistent explanation of the acquired material, which at the end of the period of professional training is formed into a holistic picture [18].

The fulfillment of creative tasks $(52.6 \%)$ and the implementation of independent activities (70.6\%) are, in our opinion, in the same educational plane, since creativity always presupposes individual efforts arising in the process of independent activity. In this regard, it would be fair to note that creative and independent activity can form a certain range of communicative (especially written and thinking) skills of a conceptual order. It is these skills that form the basis of any professional activity and represent the potential on the basis of which further human communication skills develop [18].

\section{Conclusions}

Based on the results of this study it seems to us the most logical to conclude that practiceoriented technologies constitute a special conceptual layer of educational pedagogical technologies aimed at the formation of the most competitive, relevant, thinking and socially active specialist who is able to carry out not only direct professional activities, but also to take part in the process of interpersonal communication and be at the center of information exchange processes.

Such technologies underlie the improvement of communicative competencies aimed at social adaptation and socialization of the university graduate, as well as at the development of his personal potential. The formation of such competencies has occupied a special niche in the system of modern higher professional education for a long period of time and is becoming one of the most problematic aspects of the vocational training system. In this regard, it is especially important to pay scientific attention to the study of this topic, as well as to the solution of problems arising within its framework.

\section{References}

1. F.B. Abaeva, Practice-oriented approach in teaching a foreign language to undergraduates - future teachers, 4 (13) (2015)

2. E.M. Bastrikova, Communicative competence as a linguodidactic phenomenon, Russian and Comparative Philology: Linguoculturological Aspect, $43-48$ (2004)

3. N.P. Bakharev, E.A. Dragunova, Formation of professional competencies of university students in the context of a continuous multi-level education system and targeted training for an industrial enterprise, 4 (19) (2014)

4. T.A. Belova, N.V. Grigorieva, Professionally oriented teaching as a means of forming the sociocultural competence of future economists, 1 (2014)

5. E.N. Belyaeva, Modern trends in the professional training of a teacher, 1 (2014) 
6. M.A. Bocharnikova, The concept of "communicative competence" and its formation in the scientific environment, 8 (2009)

7. Yu.M. Vasina, E.V. Panferova, A.E. Yakovleva, Implementation of practice-oriented education through modern technologies of teaching students at the university, 55-58 (2015)

8. E.E. Dudkovskaya, Development of the communicative competence of students in the context of the implementation of the Federal State Educational Standard, 3 (40) (2014)

9. E.Yu. Yesenina, Dual training: Opportunities, limitations, conditions and practice of use, 8 (2015)

10. E.F. Zeer, Self-regulating teaching as a psychological and didactic technology for the formation of competencies in students, 3 (2004)

11. V.V. Istomin, About practice-oriented training in secondary vocational education, 1 (21) (2019)

12. O.F. Karmadonova, Development of communicative skills of students and correction of communication of adolescents in the lessons of the Russian language: dis, Cand. ped. sciences., 223 (1999)

13. A.G. Mironova, L.A. Kuzmenko, D.S. Krasnova, Context-competence approach in training bachelors of the direction "Professional training (by branches)", 274-277 (2015)

14. A.V. Mordovskaya, Interactive educational technologies at the university: textbook (2013)

15. G.Kh. Murtazin, Practice-oriented technologies in the training of specialists in public relations, 12 (2010)

16. E.I. Mychko, Practice-oriented technologies in modern vocational training, 2 (2016)

17. M.M. Nazar, The use of practice-oriented technology in teaching students of secondary schools, 7 (2015)

18. M.M. Olesova, Application of practice-oriented teaching technologies in the university, 7-2 (73) (2017)

19. V.V. Okhotnikova, N.N. Surtaeva, Questions of communicative competence in training specialists at a university, 118 (2002)

20. S.S. Polisadov, Practice-oriented education at the university, 2 (2004)

21. D.A. Savitskaya, Practice-oriented technologies in the organization of school methodical work, 3 (2008)

22. G.A. Samodova, Teacher and practice-oriented technologies of his training in the system of RPAs, 190 (2004)

23. K.F. Sedov, Discourse and personality: the evolution of communicative competence, 320 (2004)

24. A.R. Sivtseva, Interactive technologies as a means of forming students' communicative competence, 5 (2017)

25. E.P. Sichinsky, Practice-oriented or dual education: on the formation of the conceptual apparatus, 1 (2018)

26. L.E. Solyankina, Model for the development of professional competence in a practiceoriented educational environment, 1 (2011)

27. M.P. Kharitonova, Formation of key competencies in education (2012) 